\title{
Inhibition of catechol-O-methyltransferase (COMT) by some plant-derived alkaloids and phenolics
}

\author{
Dilek Yalcin, Oguz Bayraktar* \\ Department of Chemical Engineering, Bioreaction Engineering Laboratory, Izmir Institute of Technology, Gulbahce Koyu, 35437 Urla-Izmir, Turkey
}

\section{A R T I C L E I N F O}

\section{Article history:}

Available online 3 May 2009

\section{Keywords:}

COMT

Inhibition

Alkaloids

Phenolics

Parkinson's disease

\begin{abstract}
A B S T R A C T
In this study, as an alternative to the medicines, natural compounds extracted from plant species (Peganum harmala, Cistus parviflorus and Vitex agnus-cactus) were investigated in order to inhibit the catechol$O$-metyhltranferase (COMT) activity. In fluorometric enzyme assay, S-adenosylmethionine (SAM) and aesculetin (ES) were used as methyl donor and acceptor substrates, respectively. Their $K_{\mathrm{m}}$ values were determined as $3.5 \pm 0.3 \mu \mathrm{M}$ and $6.4 \pm 0.4 \mu \mathrm{M}$ in absence of inhibitor. Inhibition performances of the plantderived polyphenolics and alkaloids were determined. Inhibitory effect of alkaloids extracted from $P$. harmala seeds was found the highest among the plant extracts; however, it was lower than that of 3,5DNC. In case of inhibition mechanism, mixed type inhibition was observed for alkaloid extract whereas uncompetitive inhibition was observed for 3,5-DNC. In case of polyphenolic extracts obtained from $C$. parviflorus and $V$. agnus-cactus leaves, mechanism were also explained as mixed type inhibition and their $\alpha K_{\mathrm{i}}$ values were calculated as $1.99 \pm 0.35 \mu \mathrm{g} / \mathrm{ml}$ and $9.48 \pm 0.58 \mu \mathrm{g} / \mathrm{ml}$, respectively.
\end{abstract}

(c) 2009 Elsevier B.V. All rights reserved.

\section{Introduction}

Since ancient times, plants have been used as medicine against certain human diseases. In the last century, the use of natural sources as medicine has expanded and there is a growing interest in obtaining biologically active compounds from natural sources. These compounds have antioxidant, antimicrobial, antiinflammatory and neuroprotective properties and classified as phytochemicals include most of catecholic structures [1,2]. In administration of catechols, it is known that they are methylated by an enzyme known as catechol-O-metyhltranferase (COMT; EC 2.1.1.6) that plays an important role in Parkinsonism [3]. The primary function of COMT is to deactivate biologically active catechols like catecholamine neurotransmitters (dopamine, epinephrine), levodopa (L-DOPA), carbidopa and flavonoids [4,5].

In current therapies for Parkinson's disease, selective COMT inhibitors, mainly synthetic nitrocatechol compounds (entacapone, tolcapone), are used in combination with L-DOPA and dopa decarboxylase inhibitors, although there are several well-known adverse side effects of these drugs [4,5]. Therefore, researchers have focused on the potency of natural products having ability of inhibiting COMT. Among several natural sources, tea catechins have been mostly investigated compounds by several research groups $[6,4,7]$.

\footnotetext{
* Corresponding author. Tel.: +90 232750 6681; fax: +90 2327506645.

E-mail addresses: dilekyalcin@iyte.edu.tr (D. Yalcin), oguzbayraktar@iyte.edu.tr (O. Bayraktar).
}

All of them revealed that flavonoids in $C$. sinensis have great inhibitory potency against COMT. In this study, the natural compounds extracted from the leaves of Cistus parviflorus and Vitex agnus-cactus and from the seeds of Peganum harmala were used as natural inhibitors of COMT in order to investigate the inactivation performance of methylation of aesculetin to scopoletin.

\section{Experimental}

\subsection{Materials}

$\mathrm{HCl}$ used as alkaloid extraction solvent was purchased from Merck (Germany). Petroleum ether used during the liquid-liquid extraction of alkaloids was purchased from Riedel-de Haen (Germany). All other extraction solvents were purchased from Sigma-Aldrich Chemie GmbH (Germany). COMT from porcine liver was purchased from Sigma (Germany). Other reaction mixture components including SAM, aesculetin (ES), $\mathrm{MgCl}_{2}$ anhydrous and L-cysteine non-animal source were purchased from Sigma (Germany). Potassium phosphate buffer solutions were purchased from Fluka and Merck (Germany). Dimethylsulfoxide (DMSO) used in reaction mixture was purchased from Carlo-Erba Reagents (Spain).

\subsection{Preparation of raw plant materials and extraction procedure}

The leaves of $C$. parviflorus and V. agnus-cactus were washed, dried and ground. The leaves of these two plants were extracted with $70 \%$ aqueous ethanol solution at $30^{\circ} \mathrm{C}$ for $2 \mathrm{~h}$. After evaporation 
of alcohol by using a rotary evaporator, the aqueous crude extracts were dried by using lyophilizator. The unshelled seeds of $P$. harmala were ground. The ground seeds were extracted with methanol by using a Soxhlet apparatus at $70^{\circ} \mathrm{C}$ for $8 \mathrm{~h}$. Then, methanol was evaporated to dryness. Dried particles were dissolved with $5 \% \mathrm{HCl}$ solution and it was extracted two times with $30 \mathrm{ml}$ petroleum ether, the acidic part was collected and basified to $\mathrm{pH} 9.0$ with $\mathrm{NH}_{4} \mathrm{OH}$ which was further extracted with $50 \mathrm{ml}$ chloroform for four times. Finally, chloroform layer was collected and evaporated to dryness.

\subsection{Determination of enzyme activity and inhibition study}

Enzymatic assays were performed according to the method reported by J. Veser's and M. Kurkela et al.'s studies with minor differences by using Microfluor white, 96 well plate [8,9]. The followed reaction which was catalyzed by COMT was conversion of aesculetin to scopoletin at $37^{\circ} \mathrm{C}$. Aesculetin was dissolved in dimethyl sulfoxide (DMSO) and diluted with aqueous buffer solution containing $100 \mathrm{mM}$ phosphate, $5 \mathrm{mM} \mathrm{MgCl}_{2}, 20 \mathrm{mM} \mathrm{L}$-cysteine ( $\mathrm{pH} 7.4$ ), for a final DMSO concentration of $2 \%$ in the $200 \mu$ l of reaction mixture. All other reagents were dissolved in the same buffer solution. Fluorometric measurements were performed at $355 \mathrm{~nm}$ emission and $460 \mathrm{~nm}$ excitation wavelengths for $2 \mathrm{~h}$ by using Thermo Varioskan Flash microplate reader. Enzyme concentration was kept constant at $11.0 \mu \mathrm{g} / \mathrm{ml}$ while five different SAM and five different aesculetin concentrations varied from $10 \mu \mathrm{M}$ to $100 \mu \mathrm{M}$ and from $2 \mu \mathrm{M}$ to $6 \mu \mathrm{M}$, respectively. 3,5-DNC and the crude extracts obtained from plant species were dissolved in DMSO and diluted with the buffer solution for a final DMSO concentration of $2 \%$. Final concentrations of inhibitors in $250 \mu$ l total reaction volume were given on resulting figures.

\subsection{Curve fitting and data analysis}

In data analysis, reciprocals of velocities and substrate concentrations gave the linear relationship by which $K_{\mathrm{m}}$ and $V_{\max }$ values could be calculated. The kinetic mechanism and inhibition constants were obtained by fitting the initial steady state velocity as a function of substrate concentration to the following equations defined in R.A. Copeland's book using nonlinear regression analysis program in GraphPad Prism 5.0 software [10]. The goodness of curve fit was evaluated statistically by one-way of ANOVA following with Tukey's multiple comparison test.

$$
\begin{aligned}
& v=\frac{V_{\max }[S]}{K_{\mathrm{m}}+[S]\left(1+\left([I] / \alpha K_{i}\right)\right)} \quad \text { uncompetitive inhibition } \\
& v=\frac{V_{\max }[S]}{K_{\mathrm{m}}\left(1+\left([I] / K_{i}\right)\right)+[S]} \quad \text { competitive inhibition } \\
& v=\frac{V_{\max }[S]}{K_{\mathrm{m}}\left(1+\left([I] / K_{i}\right)\right)+[S]\left(1+\left([I] / K_{i}\right)\right)} \quad \text { noncompetitive inhibition }
\end{aligned}
$$$$
v=\frac{V_{\max }[S]}{K_{\mathrm{m}}\left(1+\left([I] / K_{i}\right)\right)+[S]\left(1+\left([I] / \alpha K_{i}\right)\right)} \quad \text { mixed type inhibition }
$$

where $V_{\max }$ is the maximum enzyme velocity without inhibitor. $K_{\mathrm{m}}$ is the Michaelis-Menten constant without inhibitor. $K_{i}$ is the inhibition constant indicating the dissociation of EI complex. Alpha $K_{i}$ $\left(\alpha K_{i}\right)$ is also inhibition constant indicating the dissociation of ESI complex. In this term, Alpha $(\alpha)$ determines the mechanism by revealing the binding degree of the inhibitor which explains the affinity of enzyme for substrate [10]. At very high $\alpha$ values that is much greater than 1 , mechanism is explained by competitive inhibition and very low $\alpha$ values $(\alpha \ll 1)$ indicate uncompetitive inhibition. If it is around $1(\alpha<1$ or $\alpha>1)$ at a certain value, mechanism can be described as mixed type inhibition which explains the deviation from noncompetitive and competitive nature [10]. If it is equal to 1 , noncompetitive inhibition takes place.

\section{Results and discussion}

\subsection{Kinetic analysis to determine enzyme-substrates relationship}

Before performing inhibition study, a previous study was performed by changing substrates and enzyme concentrations in order to obtain the linear working concentration ranges of enzyme and also substrates. Enzyme concentrations were kept constant at $16.5-11.0-8.5 \mu \mathrm{g} / \mathrm{ml}$ for this experiment while seven different SAM concentrations varied from $10 \mu \mathrm{M}$ to $600 \mu \mathrm{M}$ were used against six different ES concentrations prepared at the range of $2-10 \mu \mathrm{M}$. As a result, it was found that the concentration of SAM should be kept lower than $200 \mu \mathrm{M}$ and the lowest enzyme concentration was determined as $11.0 \mu \mathrm{g}$ protein $/ \mathrm{ml}$. It was also revealed that the used concentration range of ES did not deviate from linearity. From this experiment, $K_{\mathrm{m}}$ values both for SAM and ES was obtained as $3.5 \pm 0.3 \mu \mathrm{M}$ and $6.4 \pm 0.4 \mu \mathrm{M}$ which was reported as $6.2 \mu \mathrm{M}$ in Veser's study [8].

\subsection{Kinetic analysis for inhibition study}

In inhibition study, ES concentration was kept constant at $4 \mu \mathrm{M}$ in $250 \mu$ l total reaction volume while SAM concentrations were changed from $10 \mu \mathrm{M}$ to $100 \mu \mathrm{M}$ to determine the inhibition performance with respect to SAM. Besides, inhibition with respect to ES was investigated by varying its concentrations from $2 \mu \mathrm{M}$ to $6 \mu \mathrm{M}$ at constant SAM concentration of $100 \mu \mathrm{M}$. Enzyme concentration was kept constant at $11.0 \mu \mathrm{g} / \mathrm{ml}$ for the whole assay. A representative percentage values of COMT inhibition obtained for the assay performed at $100 \mu \mathrm{M}$ SAM concentration were given in Fig. 1. Inhibition performances of crude extract of alkaloids and their standards were found as comparable to that of obtained for positive control, 3,5-DNC. In Fig. 1, it was also revealed that among polyphenolic extracts, $C$. parviflorus leaf extracts showed higher inhibition than that of $V$. agnus-cactus. As a result, alkaloids were found to be more potent COMT inhibitors than the polyphenolics and it was thought that nitro groups content of them plays important role in COMT inhibition.

Michaelis kinetic calculations supported these findings. A sharp decrease of formation rate of scopoletin, $V$ (nmol/min mg protein) was observed in presence of the positive control. The nonlinear fitting of data given in Fig. 2A obtained by using GraphPad software which was supported also by the reciprocal plot (Fig. 2B) demonstrated the uncompetitive nature of the positive control, as expected. Because, almost all nitrocatechols are known that they behave uncompetitively with respect to SAM and tight binding inhibitors of COMT [5]. From these kinetic data, the $K_{\mathrm{m}}$ value was calculated as $6.83 \pm 0.77 \mu \mathrm{M}$ and $V_{\max }$ was found as $1.07 \pm 0.02 \mathrm{nmol} / \mathrm{min}$. mg protein. Dissociation constant $\left(\alpha K_{i}\right)$ for 3,5 -DNC which was an uncompetitive inhibitor was obtained as $9.17 \pm 0.46 \mathrm{ng} / \mathrm{ml}$ (i.e., $45.60 \pm 2.29 \mathrm{nM}$ ). Also, $\mathrm{IC}_{50}$ was calculated as $44.18 \pm 0.78 \mathrm{nM}$ from dose response curve of 3,5-DNC which was very similar to that value reported in Kurkela et al.'s study as $35 \mathrm{nM}$ [9].

Moreover, the nonlinear fit of data obtained for alkaloid extract was given in Fig. $3 \mathrm{~A}$ and reciprocals of velocities were given in Fig. 3B. Dissociation constant, $\alpha K_{i}$ was found as $2.24 \pm 0.75 \mu \mathrm{g} / \mathrm{ml}$ where $\alpha$ was equal to $18.72 \pm 2.28$. Based on the criteria given in Section 2.4, the inhibition mechanism for alkaloid extract was determined as mixed type inhibition with respect to SAM unlike the uncompetitive mechanism found for positive control, 3,5- 


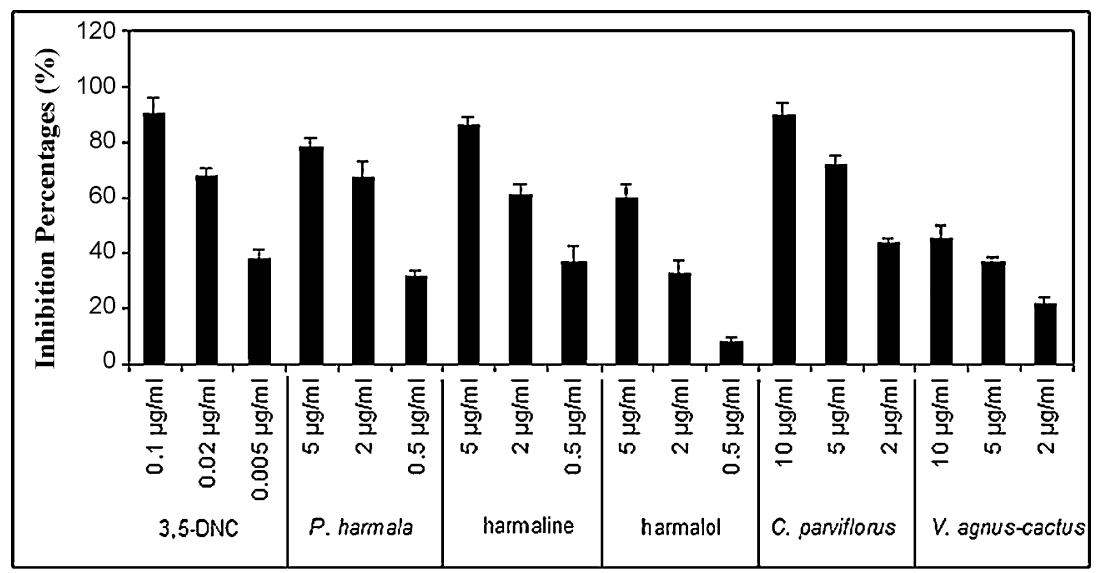

Fig. 1. Inhibition percentages of crude extracts and alkaloid standards with respect to 3,5-DNC. (SAM concentration was $100 \mu M$.)
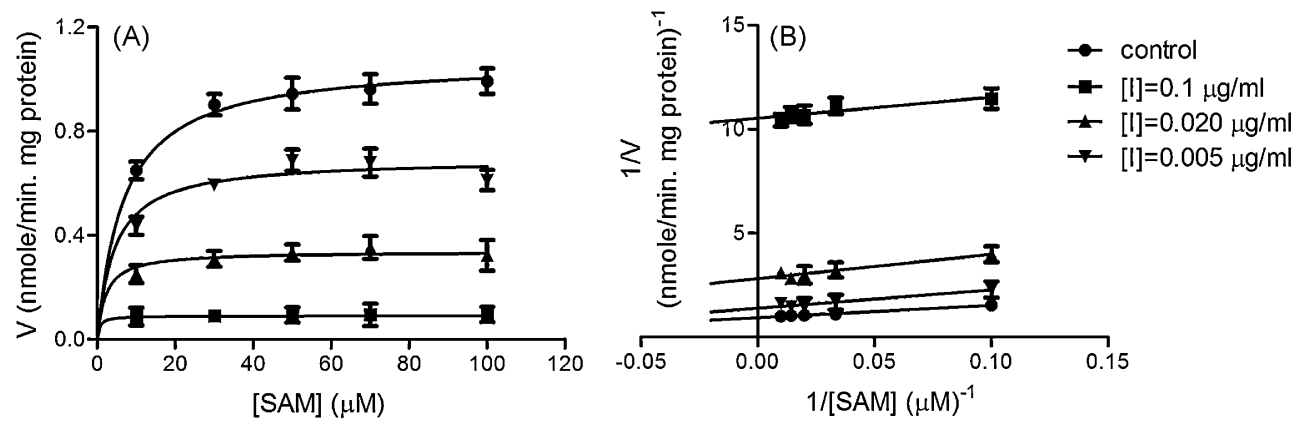

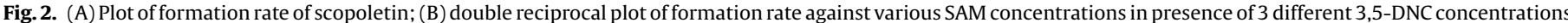
$(P<0.01$, means of inhibited ones are significantly different from control).

DNC. Besides, the inhibitory effect of this natural alkaloid extract was found significantly lower than that of 3,5-DNC. From the kinetic data, the $K_{\mathrm{m}}$ and $V_{\max }$ values were also determined as $6.05 \pm 0.69 \mu \mathrm{M}$ and $1.06 \pm 0.02 \mathrm{nmol} / \mathrm{min}$. $\mathrm{mg}$ protein, respectively. $\mathrm{IC}_{50}$ of alkaloid extracts was calculated as $1.09 \pm 0.33 \mu \mathrm{g} / \mathrm{ml}$.

It was known that $P$. harmala contains several $\beta$-carbolines like harmaline, harmine, harmalol, harmane, vasicinone, vasicine, etc. $[11,12]$. It was also reported that among these alkaloids harmaline and harmine are known as monoamineoxidase (MAO-B) inhibitors and they have several types of activities such as antioxidant, antiviral and anticancer [12,13]. Our HPLC analysis has shown that the major alkaloid in this P. harmala seed extract was harmaline. Therefore, in this study harmaline and harmalol standards were used to determine which type of alkaloids could be responsible for the inhibitory effect. In Figs. 4 and 5, the results obtained for these two alkaloid standards were given. As expected, harmaline strongly inhibited COMT by mixed type manner and its perfor- mance was found higher than that of harmalol which inhibited COMT by uncompetitive manner like positive control, 3,5-DNC.

From the data given in Figs. 4 and 5, it was found that the obtained dissociation constant for harmaline were closer to that of crude alkaloid extract compared to those determined for harmalol. The $\alpha K_{i}$ value for harmaline were found as $1.36 \pm 0.11 \mu \mathrm{g} / \mathrm{ml}$ having $\alpha$ value of $2.49 \pm 0.78$. The lower $\alpha$ value obtained for harmaline compared to that of found for P. harmala extract (18.72 \pm 2.28$)$ can be explained by shift in the dominant inhibition mechanism from competitive to noncompetitive. The total net inhibitory effect was reflected and explained by mixed type inhibition. The $\alpha K_{i}$ of harmalol was obtained as $3.21 \pm 0.16 \mu \mathrm{g} / \mathrm{ml}$. Besides, $\mathrm{IC}_{50}$ values of harmaline and harmalol were calculated as $0.98 \pm 0.12 \mu \mathrm{g} / \mathrm{ml}$ $(4.57 \pm 0.14 \mu \mathrm{M})$ and $3.59 \pm 0.37 \mu \mathrm{g} / \mathrm{ml}(13.19 \pm 0.31 \mu \mathrm{M})$, respectively.

It was reported by several researchers that polyphenolics mainly tea catechins, gallic acid and hydroxybenzoic acid derivatives have
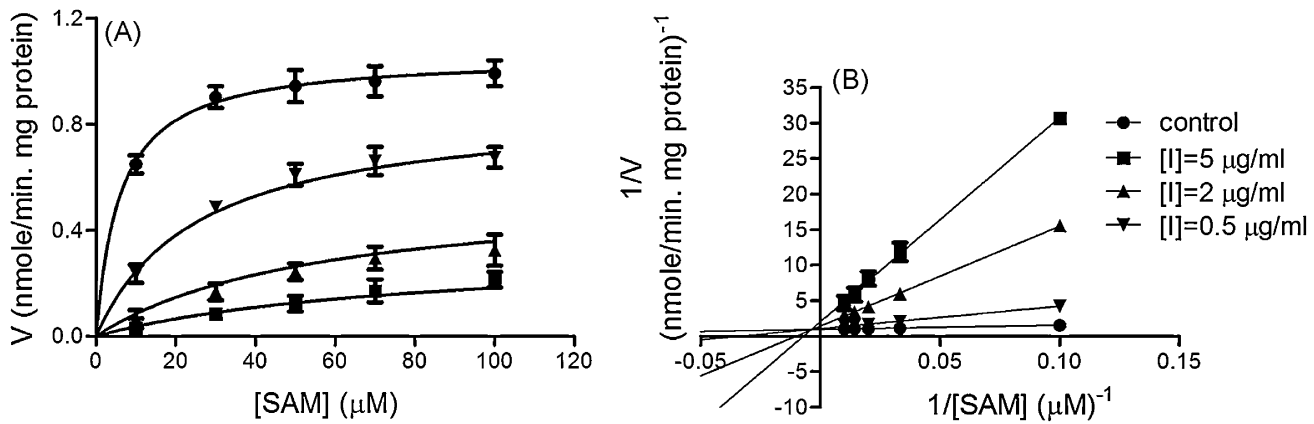

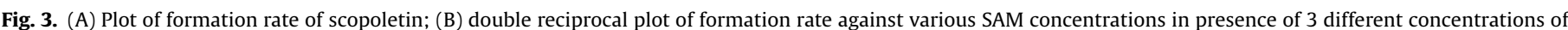
crude alkaloid extracts obtained from $P$. harmala seed $(P<0.01$, means of inhibited ones are significantly different from control). 

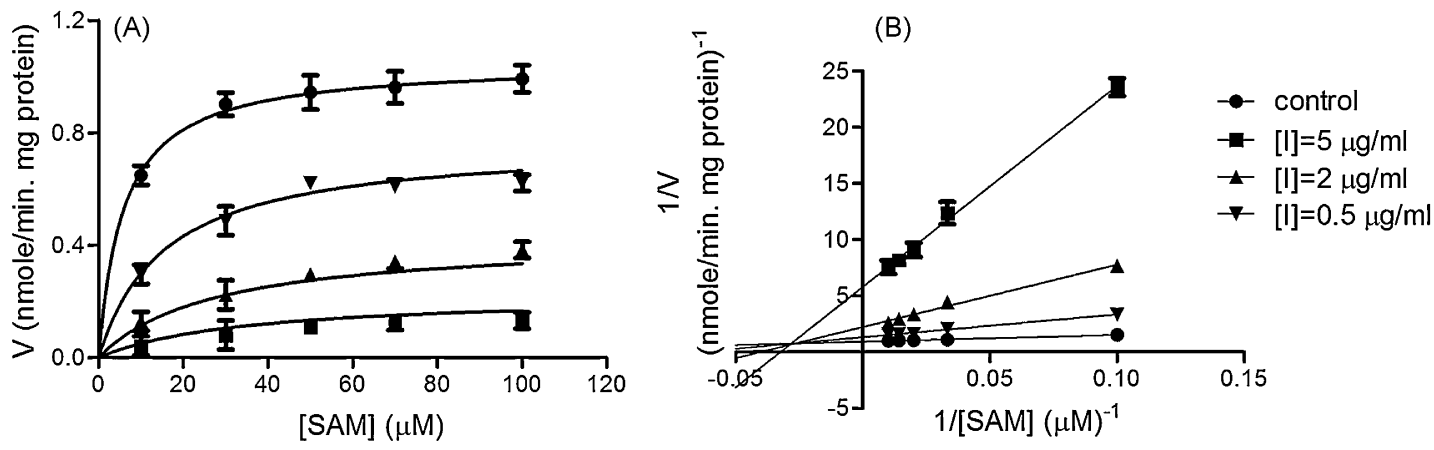


harmaline $(P<0.01$, means of inhibited ones are significantly different from control).
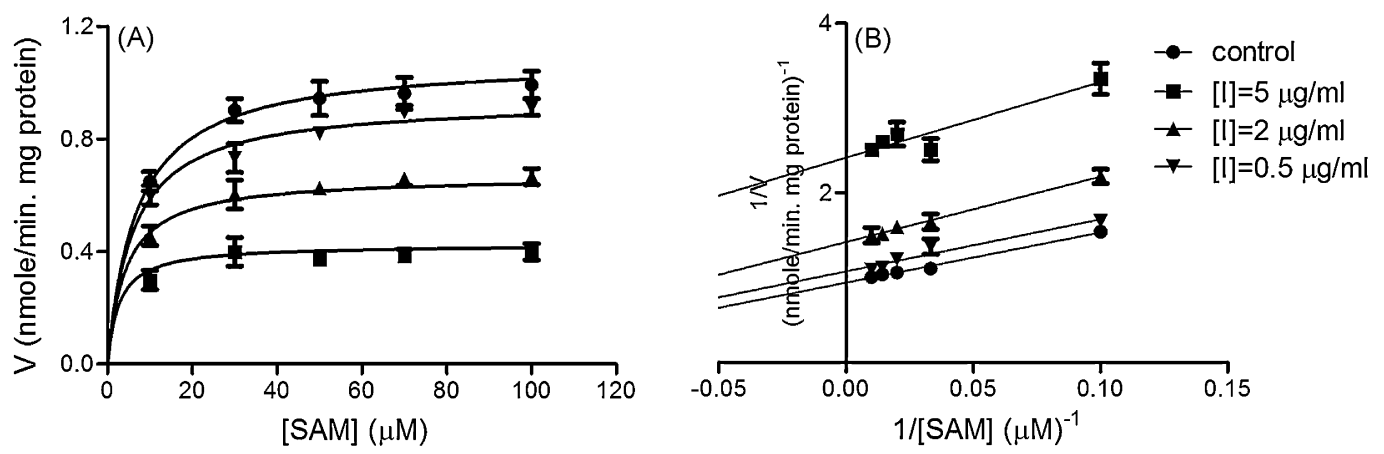

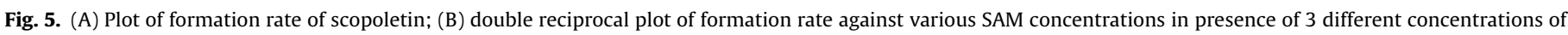
harmalol $(P<0.01$, means of inhibited ones are significantly different from control).

inhibitory effect on COMT $[4,7,16]$. Therefore, extracts of $V$. agnuscactus and $C$. parviflorus leaves having high polyphenol content were used in inhibition study. As seen in Fig. 1, the crude alkaloid extract and its standards showed higher inhibition potency than polyphenolic extracts obtained from V. agnus-cactus and $C$. parviflorus leaves.

Scopoletin formation rate was also decreased in presence of $V$. agnus-cactus extract. Mechanism was determined as mixed type with respect to SAM from nonlinear fit of data given in Fig. 6A supported with double-reciprocal plot of formation rate that was given in Fig. 6B. Dissociation constant, $\alpha K_{i}$ was found as $9.48 \pm 0.58 \mu \mathrm{g} / \mathrm{ml}$ where $\alpha$ was $2.14 \pm 0.23$ that indicates inhibition was obviously closer to noncompetitive when the criteria given in Section 2.4 was taken into consideration. The apparent $K_{\mathrm{m}}$ and $V_{\max }$ values were calculated as $5.84 \pm 0.90 \mu \mathrm{M}$ and $1.03 \pm 0.02 \mathrm{nmol} / \mathrm{min}$. $\mathrm{mg}$ protein. From dose-response curve, $\mathrm{IC}_{50}$ value for $\mathrm{V}$. agnus-cactus was determined as $12.96 \pm 0.29 \mu \mathrm{g} / \mathrm{ml}$. Inhibition performance of $V$. agnus-cactus extract was relatively lower than that of $P$. harmala seed extract. This was an expected result, since the main polyphenol content of $V$. agnus-cactus extract was gallic acid, p-hydroxybenzoic acid, rutin and ferulic acid which were known the examples of first generation COMT inhibitors. It was also known that the inhibition performances of them much lower than that of nitrocatechols $[5,16]$. Beside that, this plant contains some estrogenic compounds like linoleic acid and also halimane and labdane type diterpenoids which were also thought having possibility of inhibitory effect [14].

Similar observations were obtained for the crude extracts of $C$. parviflorus leaves. Changes in the formation rate against different SAM concentrations in absence and presence of inhibitors were given in Fig. 7. From the reciprocal plot (Fig. 7B) of the nonlinearly fitted curves (Fig. 7A), it was obtained that $C$. parviflorus leaf extract inhibited COMT also in mixed type manner with respect to SAM like it was found for the other plant extracts used in this study. The $\alpha K_{i}$ value for C. parviflorus leaf extracts was found as $1.99 \pm 0.35 \mu \mathrm{g} / \mathrm{ml}$ and $\alpha$ was calculated as $0.79 \pm 0.32$. The closest $\alpha$ value to 1.0 supported inhibition was more similar to noncompetitive profile
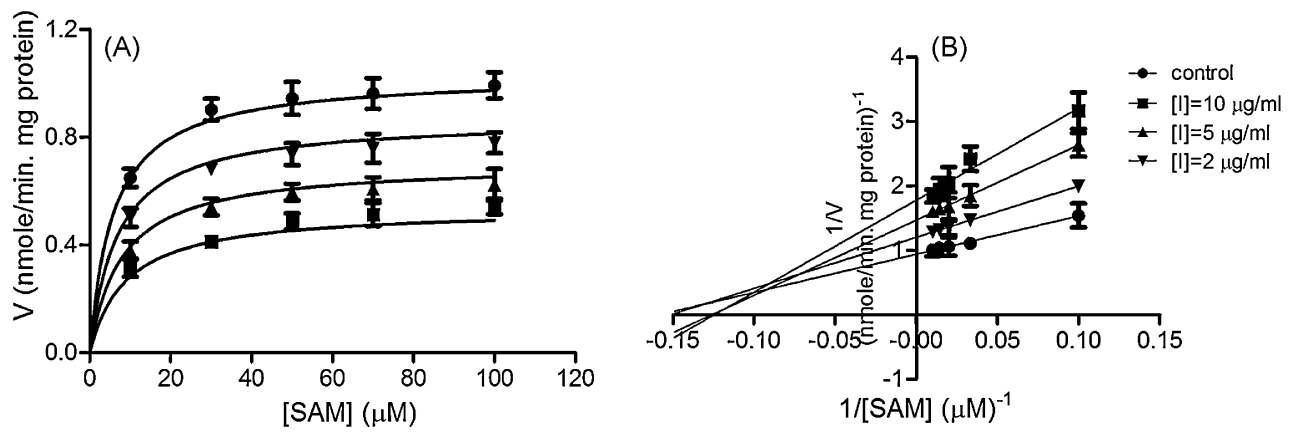

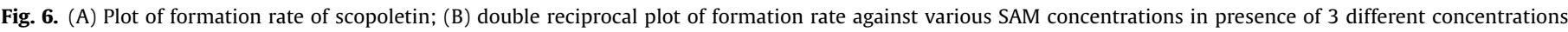

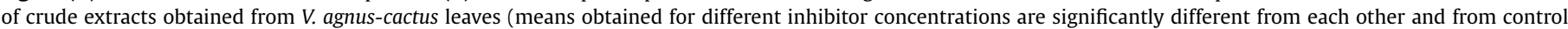
$(P<0.01))$. 



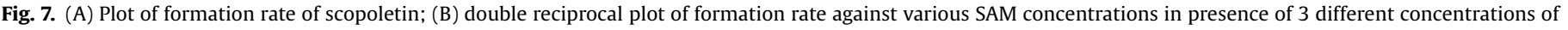



for $C$. parviflorus leaf extracts as seen from double-reciprocal plot given in Fig. 7B. The apparent $K_{\mathrm{m}}$ and $V_{\max }$ values were obtained $6.02 \pm 1.29 \mu \mathrm{M}$ and $1.06 \pm 0.04 \mathrm{nmol} / \mathrm{min} \mathrm{mg}$ protein, respectively. $\mathrm{IC}_{50}$ value for this plant extract was found as $2.44 \pm 0.09 \mu \mathrm{g} / \mathrm{ml}$ which revealed that this plant extract showed 5 times stronger inhibitory activity than that of V. agnus-cactus, however it was about 2 times lower when it was compared to the extracts of $P$. harmala.

The known high terpenoid and flavonoid content of leaves of C. parviflorus were thought to be responsible for high inhibitory effect which could be caused by the relaxation activity reported by other researchers [17]. Also, it was known that this plant composed of numerous terpenoid essential oils like carvacrol, thymol, manoyl oxides and also esters like sabinene hydrate acetate, benzyl benzoate [15]. However, in order to determine the found inhibitory effect of this polyphenolic extract on COMT, further investigations are still needed.

\section{Conclusion}

The alkaloid extracts obtained from $P$. harmala seed were found as the most potent inhibitors among the three different plant species. However, the inhibition performance of $P$. harmala seed extract was significantly less than the performance of 3,5-DNC. The relatively high harmaline content of crude extracts obtained from $P$. harmala seed was thought to be responsible for the observed inhibitory effect. The inhibition mechanisms for both extract and harmaline were explained by mixed type inhibition model while it was determined as uncompetitive for 3,5-DNC.

On the other hand, the polyphenolic extracts of $C$. parviflorus and $V$. agnus-cactus leaves were found as less effective COMT inhibitors than alkaloids. Among these polyphenolics, the extract of $C$. parviflorus showed higher inhibitory effect than that of $V$. agnus-cactus. Both polyphenolic extracts inhibited COMT in mixed type manner with respect to SAM having different $\alpha$ values.
As a result of this study, it was observed that natural compounds obtained from $P$. harmala and $C$. parviflorus can be an alternative source of medicine in treatment of Parkinson's disease.

\section{Acknowledgements}

Support from the Turkish Scientific Research Council under Project MAG-107M307 and from the Izmir Institute of Technology under Project 2007IYTE04 is gratefully acknowledged.

\section{References}

[1] M.C. Heath, Physicol. Mol. Plant Pathol. 61 (2002) 1-2.

[2] M.B.M. van Duursen, J.T. Sanderson, P. Chr. de Jong, M. Kraaij, M. van den Berg, Toxicol. Sci. 81 (2004) 316-324.

[3] M.J. Bonifacio, M.A. Vieira-Coelho, P. Soares-da-Silva, Eur. J. Pharmacol. 460 (2003) 163-170.

[4] D. Chen, C.Y. Wang, J.D. Lambert, N. Ai, W.J. Welsh, C.S. Yang, Biochem. Pharmacol. 69 (2005) 1523-1531.

[5] M.J. Bonifacio, P.N. Palma, L. Almeida, P.S. Silva, CNS Drug Rev. 13 (2007) $352-379$.

[6] O. Weinreb, S. Mandel, T. Amit, M.B.H. Youdim, J. Nutr. Biochem. 15 (2004) 506-516.

[7] M. Kadowaki, E. Ootani, N. Sugihara, K. Furuno, Biol. Pharm. Bull. 28 (2005) 1509-1513.

[8] J. Veser, J. Bacteriol. 169 (1987) 3696-3700.

[9] M. Kurkela, A. Siiskonen, M. Finel, P. Tammela, J. Taskinen, P. Vuorela, Anal. Biochem. 331 (2004) 198-200.

[10] R.A. Copeland, Enzymes: A Practical Introduction to Structure, Mechanism and Data Analysis, second ed., Wiley, New York, 2000.

[11] B. Grella, M. Dukat, R. Young, M. Teitler, K. Herrick-Davis, C.B. Gauthier, R.A Glennon, Drug Alcohol Depend. 50 (1998) 99-107.

[12] H. Pulpati, Y.S. Biradar, M. Rajani, J. AOAC Int. 91 (2008) 1179-1185.

[13] J.H. Halpern, Pharmacol. Ther. 102 (2004) 131-138.

[14] M. Ono, T. Yamasaki, M. Konoshita, T. Ikeda, M. Okawa, J. Kinjo, H. Yoshimitsu, T. Nohara, Chem. Pharm. Bull. 56 (2008) 1621-1624.

[15] D. Angelopoulou, C. Demetzos, D. Perdetzoglou, Biochem. Syst. Ecol. 29 (2001) 405-415.

[16] C. Proestos, M. Komaitis, J. Food Qual. 29 (2006) 567-582.

[17] B. Somoza, V.R. Sanchez de Rojas, T. Ortega, A.M. Villar, Phytother. Res. 10 (1996) 304-308. 